\title{
Functional interaction of adenovirus E1A with holo-TFIID
}

\author{
Thomas G. Boyer and Arnold J. Berk ${ }^{1}$ \\ Molecular Biology Institute, Department of Microbiology and Molecular Genetics, University of California, \\ Los Angeles, Los Angeles, California 90024-1570 USA
}

\begin{abstract}
The activation domains of several regulatory transcription factors have been shown to bind directly in vitro to the TATA box-binding protein (TBP). Yet TBP must also interact with multiple associated polypeptides, called TAFs, for these same activators to stimulate transcription. These findings raise the question of how TBP can interact with so many proteins, both activators and TAFs, simultaneously. Here, we show that the activation domain of the adenovirus large E1A protein can bind specifically and stably to isolated holo-TFIID, the multisubunit protein complex consisting of TBP plus TAFs. Consequently, the surface of TBP that interacts with E1A must be exposed in the holo-TFIID complex. To assess the functional significance of this interaction, we established an in vitro transcription system responsive to the E1A activation domain. The addition of excess E1A to this system inhibits (squelches) both E1A-dependent and E1A-independent transcription by sequestering a target factor required for E1A activation. From among the component activities that collectively reconstitute E1A-responsive transcription in this system, holo-TFID alone is singularly capable of reversing the inhibition of transcription mediated by excess E1A, indicating that holo-TFIID is the direct functional target of the E1A activation domain.
\end{abstract}

[Key Words: Transcription; transcription factors; transcriptional activation; RNA polymerase II; TAFs; activation domain]

Received March 2, 1993; revised version accepted June 25, 1993.

Recent studies on the mechanism of transcriptional stimulation by activator proteins raise a significant conceptual difficulty. Several activation domains have been shown to bind directly to the TATA box-binding polypeptide (TBP) in vitro (Stringer et al. 1990; Horikoshi et al. 1991; Lee et al. 1991; Lieberman and Berk 1991). The strength and specificity of these interactions suggest that direct binding to TBP is an important component of the activation mechanism for these activators. Moreover, mutations in a truncated VP16 activation domain and in the adenovirus large E1A protein, which decrease affinity for TBP in vitro, reduce activation in vivo (Ingles et al. 1991; Lee et al. 1991; J. Geisberg, W.S. Lee, A.J. Berk, and R.P. Ricciardi, unpubl.). The present difficulty arises from the discovery that in higher eukaryotes TBP is only one subunit of a large protein complex required for activated transcription by RNA polymerase II (Dynlacht et al. 1991; Tanese et al. 1991; Zhou et al. 1992; Hoey et al. 1993). TBP associates with different TBP-associated factors (TAFs) in distinct multisubunit proteins required for transcription by each of the three nuclear RNA polymerases (Rigby 1993). Although it was postulated initially that there might be multiple complexes of TBP and TAFs involved in transcription by RNA polymerase II, recent results suggest that there is a single complex re-

${ }^{1}$ Corresponding author. quired for activation by several different classes of activator proteins (Zhou et al. 1992; Hoey et al. 1993). For clarity, we refer to this complex as holo-TFIID. At least six TAFs associate with TBP in Drosophila holo-TFIID (Dynlacht et al. 1991), whereas at least eight TAFs associate with TBP in human holo-TFIID (Zhou et al. 1992, 1993). The question that arises is how can TBP interact simultaneously with so many polypeptides, including TAFs and activation domains? The problem is compounded because activation domains and TAFs (Zhou et al. 1993) interact with the conserved 180-residue carboxy-terminal core domain of TBP. Furthermore, the general transcription factors TFIIA and TFIIB also interact with the conserved core domain of TBP during transcription complex assembly (for review, see Zawel and Reinberg 1992). The three-dimensional structure of the TBP conserved core domain (Nikolov et al. 1992) predicts that the DNA-bound protein has considerable surface area to accommodate interactions with multiple proteins. Still, the question remains as to whether transcriptional activation domains can interact directly with the TBP subunit when it is assembled into its native holo-TFIID form. We have addressed this question directly by analyzing the interaction between the E1A activation domain and purified holo-TFID and by exploring the functional significance of the interaction in in vitro transcription reactions. 
The adenovirus large E1A protein is a multifunctional polypeptide that stimulates transcription from both viral and cellular genes. In addition to its function as a potent activator of gene transcription, E1A manifests other biochemical activities sufficient to modulate progression through the cell cycle, immortalize primary cells in culture, and cooperate with the adenovirus E1B gene products to induce complete cellular transformation (Moran et al. 1986; Moran and Mathews 1987; Nevins 1992). These pleiotropic effects derive from the combinatorial presence within the large ElA protein of three distinct regions that are highly conserved among different human adenovirus serotypes (Moran and Mathews 1987). With respect to transcriptional stimulation, mutational analysis has demonstrated that the trans-activation function of ElA resides principally within conserved region 3 (CR 3) (Flint and Shenk 1989).

The independent transcriptional stimulatory potential of CR 3 was demonstrated initially by the ability of a synthetic peptide comprising the 49-amino-acid region to activate transcription from an early adenovirus promoter after microinjection into fibroblasts (Lillie et al. 1987). A potential explanation for the ability of CR 3 to function independently as an activator of transcription derived from its subsequent molecular dissection using targeted mutagenesis. These studies revealed that CR 3 manifests two properties characteristic of prototypic eukaryotic transcriptional activators: (1) a domain that directs ElA to its target promoter, and (2) a transcriptional activation domain that enables the promoter-bound activator to stimulate transcription (Lillie and Green 1989; Webster and Ricciardi 1991).

At its carboxyl terminus, CR 3 harbors a domain responsible for promoter targeting. Distinct from the binding domains associated with typical cellular activators that often use sequence-specific contacts with promoter DNA, the promoter-binding domain of CR 3 is postulated to direct E1A to a specific transcription unit through interactions with promoter-bound cellular transcription factors (Lillie and Green 1989). This observation serves to explain how E1A can stimulate transcription from a diverse array of unrelated promoter sequences with only very low affinity for DNA and no apparent sequence specificity (Berk 1986; Chaterjee et al. 1988; Flint and Shenk 1989).

A contiguous stretch of 30 amino acid residues at the amino terminus of CR 3 collectively constitutes a domain required for trans-activation (Martin et al. 1990). The outstanding structural feature within this region is a C4-type zinc finger, the integrity of which is essential for the function of CR 3. Mutation of any one of the four cysteine residues that collectively define the finger motif abolishes its trans-activating capability (Culp et al. 1988; Martin et al. 1990; Webster and Ricciardi 1991). The mechanism by which the finger region stimulates target gene transcription is largely unknown. However, an intact finger region is known to be required for trans-dominant phenotypes conferred on CR 3 by mutation of its carboxyl promoter-binding domain (Webster and Ricciardi 1991). This observation has been interpreted to im- ply that the finger region of CR 3 binds a limiting cellular transcription factor.

Collectively, data derived from mutational analysis thus predict a model for E1A trans-activation in which the activation domain of CR 3 is directed to a target promoter by an interaction of its carboxyl region with a DNA-bound sequence-specific transcription factor. Once tethered to the promoter, transcriptional stimulation by the activation domain is mediated through direct or indirect contacts between its finger region and one or more components of the general transcription machinery. This model is supported by a growing body of genetic and biochemical evidence. First, genetic studies suggest that the carboxyl region of CR 3 interacts with activating transcription factor-2 (ATF-2), a member of the cAMP response element-binding (CREB)/ATF family of sequence-specific DNA-binding transcription factors (Liu and Green 1990). Consistent with this observation, ATF-2-binding sites are present in several E1A-responsive promoters. Second, several lines of evidence suggest that the cellular factor targeted by the finger region of CR 3 is TFIID, the multisubunit general transcription factor that binds to the TATA box element, thereby nucleating the assembly of initiation complexes containing the remaining general factors and RNA polymerase II. Specifically, the transcriptional activity of a partially purified TFIID-containing fraction from HeLa cells has been demonstrated to be increased after an adenovirus infection (Leong et al. 1988). Furthermore, a subset of E1A-responsive promoters appear to require only the TATA box for trans-activation (Wu et al. 1987; Simon et al. 1988). Finally, it has been directly demonstrated that the finger domain of CR 3 binds both specifically and stably to isolated TBP, the sequence-specific DNA-binding subunit of TFIID (Horikoshi et al. 1991; Lee et al. 1991).

Despite the compelling nature of these data, the molecular mechanism by which E1A CR 3 functions to stimulate target gene transcription remains to be elucidated. As discussed above, the functional relevance of the observed interaction between CR 3 and TBP has not been established definitively. In the present study, we demonstrate that CR 3 can bind in vitro to the TBP subunit of purified holo-TFIID. Consequently, the surface of TBP that interacts with CR 3 must be accessible in the holo-TFIID complex. In an effort to assess the functional significance of this interaction, we established conditions in vitro that will reproducibly support transcriptional stimulation by CR 3. Using this E1A-responsive in vitro transcription system, we found that addition of high concentrations of CR 3 inhibits both E1A-dependent and E1A-independent transcription, a phenomenon referred to as transcriptional "squelching" /Gill and Ptashne 1988; Sadowski et al. 1988; Triezenberg et al. 1988). Significantly, both activation and inhibition of transcription mediated by CR 3 exhibited identical mutational sensitivities; individual point mutations that impaired activation caused a corresponding reduction in the ability of CR 3 to inhibit transcription at high concentrations. This observation suggests that both activa- 
tion and inhibition involve an identical interaction between a surface on CR 3 and a target factor in the general transcription machinery. We exploited the ability of $C R$ 3 to inhibit its own transcription in vitro in an effort to identify its functional target. Under conditions of inhibited transcription mediated by high concentrations of CR 3, activated transcription is restored only by the addition of purified holo-TFIID. Inhibition is not reversed by TBP in the absence of TAFs or any of the other general factor fractions required to reconstitute E1A trans-activation in vitro. These observations provide direct functional evidence that E1A CR 3 stimulates transcription through a direct association with holo-TFIID.

\section{Results}

\section{E1A CR 3 stimulates transcription in vitro}

The indirect association of E1A with its target promoters by interactions involving its carboxy-terminal domain and DNA-bound sequence-specific transcription factors poses several technical difficulties in establishing conditions in vitro that will support ElA-dependent transcription. First, a candidate sequence-specific DNA-binding protein that exhibits sufficient affinity for E1A CR 3 must be identified and available in sufficient biochemical quantities. Second, conditions must be established in vitro that simultaneously favor the association of this protein with E1A and DNA, and these conditions must be compatible with transcription in vitro. To circumvent these complexities, we exploited the system of Lillie and Green (1989) to study transcriptional activation by El A in vivo. An ElA fragment encompassing CR 3 (ElA amino acids 121-223) was fused to the DNA-binding domain of the yeast transcriptional activator GAL4 (GAL4 amino acids 1-147), thereby generating the fusion protein GAL4-ElA (Lillie and Green 1989). In this configuration, E1A CR 3 is directed efficiently by the GAL4 DNA-binding domain to a target promoter bearing GAL4 DNA-binding sites. It has been demonstrated previously that GAL4-E1A will function in vivo as a potent activator of transcription when assayed from a promoter template bearing GAL4 DNA-binding sites (Lillie and Green 19891.

We expressed GAL4-E1A in Escherichia coli, purified it, and tested its ability to stimulate transcription in an unfractionated HeLa cell nuclear extract from a synthetic promoter template bearing five tandem GAL4 DNA-binding sites positioned immediately upstream of the adenovirus E4 TATA box (Carey et al. 1990a). As a negative control, we tested in parallel a GAL4-E1A derivative in which two of the four conserved cysteine residues, which structurally define the zinc finger of CR 3 , have been changed to alanine residues. This double point mutant, GAL4-E1A 171A/174A, has been demonstrated previously to be transcriptionally inactive in vivo, thereby demonstrating the requirement for an intact finger motif for the activation function of CR 3 (Culp et al. 1988; Martin et al. 1990).

In the absence of exogenously added GAL4-E1A, the nuclear extract supported a very low level of basal transcription (Fig. 1, lane 1). The addition of GAL4-E1A to the nuclear extract, however, resulted in a marked stimulation of transcription above this basal level. The maximum level of transcriptional stimulation was observed with 0.24 pmoles of activator, an amount of protein roughly equivalent to 3 footprint units (fpu) of DNAbinding activity (Fig. 1, lane 3). (One footprinting unit is the amount of GAL4-E1A required to completely fill all five GAL4 DNA-binding sites present in $100 \mathrm{ng}$ of the target promoter in the absence of other proteins as assayed by DNase I footprinting.) The addition of GAL4E1A above 0.24 pmoles failed to produce a further increase in the level of activated transcription (Fig. 1, lane 2). In repeated experiments involving multiple titrations of GAL4-E1A, maximal levels of transcriptional stimu-

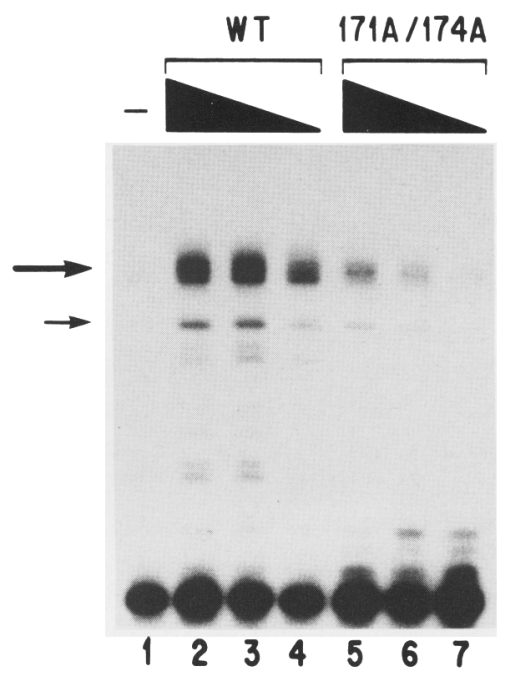

REPORTER :

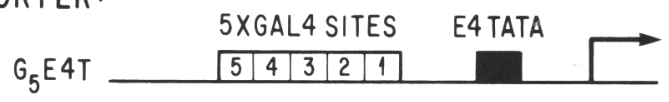

ACTIVATORS:

$$
\text { GAL4-EIA WT GAL4(1-147) EIACCSCCI(121-223) }
$$

\section{GAL4-E1A 171A/174A GAL4(1-147) EIACC:AA](121.223)}

Figure 1. GAL4-E1A stimulates transcription in vitro in a HeLa cell nuclear extract. A primer extension analysis of transcripts synthesized in vitro from the $\mathrm{pG}_{5} \mathrm{E} 4 \mathrm{~T}$ reporter template is shown. Transcription reactions were performed in a HeLa cell nuclear extract, as described in Materials and methods, in the absence (lane 1) or in the presence of decreasing concentrations of GAL4-E1A (lanes 2-4) or GAL4-E1A 171A/174A (lanes 5-7). The amount of each activator added to in vitro transcription reactions corresponds to 0.08 pmoles (lanes 4,7 ), 0.24 pmoles (lanes 3,6), and 0.72 pmoles (lanes 2,5). The position of the major specific transcripts are indicated by arrows. Schematic diagrams of the $\mathrm{pG}_{5} \mathrm{E} 4 \mathrm{~T}$ reporter template (transcription initiation site designated by the right-angled arrow) and the activators used are depicted below. 
lation were obtained with $0.1-0.6$ pmoles of input activator, an amount of protein that corresponds roughly to 1.5-7.5 fpu of DNA-binding activity.

By comparison to GAL4-E1A, the double point mutant GAL4-E1A 171A/174A was impaired significantly in its ability to stimulate transcription despite the addition of an equivalent amount of both proteins (Fig. 1, lanes 5-7). The residual level of transcriptional activity observed with GAL4-E1A 171A/174A could derive either from residual transcriptional stimulatory activity within CR 3 or, alternatively, from a cryptic activation domain present in the GAL4-encoded sequences of the fusion protein (Carey et al. 1990b). Regardless of the nature of this residual activation, these results establish conditions in vitro that will reproducibly support transcriptional stimulation by CR 3 in a cell-free system. Moreover, the differential activation potential of GAL4 ElA versus GAL4-E1A 171A/174A suggests that the mechanism of transcriptional stimulation mediated by CR 3 in this in vitro system mimics its mechanism of action in vivo.

\section{E1A CR 3 binds holo-TFIID}

As a first approach toward the identification of the cellular target of E1A CR 3, we fractionated HeLa cell nuclear extract by successive phosphocellulose and DEAESepharose chromatography to generate a complete set of partially purified general transcription factor fractions. These individual fractions, when recombined, support efficient transcriptional stimulation by GAL4-E1A (Zhou et al. 1992). Using this reconstituted E1A-responsive in vitro system, we have observed recently that human TBP, expressed in E. coli (rTBP), is unable to substitute for a partially purified TFIID-containing fraction to support GAL4-E1A-mediated transcriptional stimulation (Zhou et al. 1992). This observation, consistent with the known factor requirements for all eukaryotic transcriptional activators tested in vitro thus far, suggested a role for additional factors (TAFs) present in the partially purified TFIID fraction in mediating GAL4-E1A transactivation (Pugh and Tjian 1992; Zhou et al. 1992). To purify TBP in a transcriptionally active complex with TAFs, a stable HeLa-derived cell line, LTR $\alpha 3$, was established that expresses an epitope-tagged TBP (eTBP) (Zhou et al. 1992). The presence of the epitope on TBP was exploited to facilitate the immunopurification from partially purified LTR $\alpha 3$ cell nuclear extract of eTBP and TAFs using a monoclonal antibody $(\mathrm{mAb})$ specific for the epitope. This immunopurification protocol permitted the isolation of a multisubunit protein complex, termed holo-eTFIID, that is composed of TBP and at least eight additional TAFs ranging in size from 250 to $28 \mathrm{kD}$ (Zhou et al. 1992, 1993; Fig. 2). We have demonstrated that holo-eTFIID, in contrast with its isolated TBP subunit, will substitute efficiently for a partially purified TFIIDcontaining fraction to support transcriptional stimulation by GAL4-E1A ( Zhou et al. 1992). The critical requirement for TAFs in transcriptional stimulation mediated by GAL4-E1A, coupled with the previous

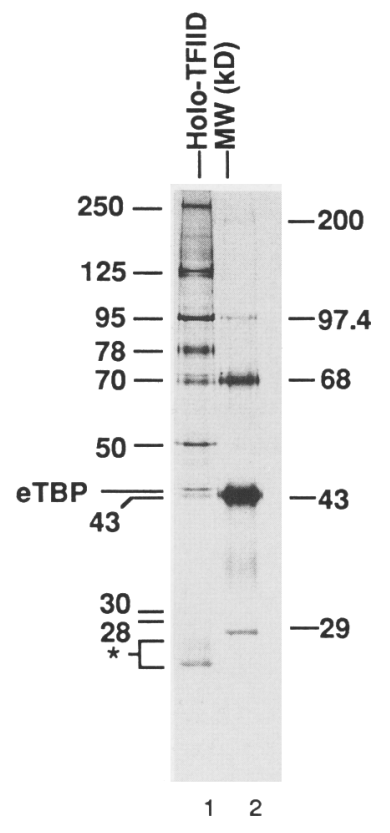

Figure 2. Polypeptide composition of the holo-eTFIID complex used in the ElA-binding experiments shown in Fig. 3 and 4. A silver-stained SDS-10\% polyacrylamide gel is shown. Lane 1 represents holo-eTFIID complex eluted with HAl peptide from a mAb 12 CA5 affinity column incubated with the phosphocellulose D fraction of the eTBP-expressing LTR $\alpha 3$ cell line as described in Materials and methods. The sizes (in $\mathrm{kD}$ ) of the individual TAFs are indicated at left. The asterisk $\left({ }^{*}\right)$ denotes antibody light-chain polypeptides. Lane 2 represents molecular mass standards, with the sizes (in $\mathrm{kD}$ ) indicated at right.

demonstration that ElA CR 3 binds $\mathrm{rTBP}$, raised the question of whether TBP in association with TAFs is accessible for interaction with ElA. To address this question we compared the ability of rTBP versus holoTFIID to bind ElA.

Epitope-tagged rTBP (reTBP) and epitope-tagged holoTFIID (holo-eTFIID) were immunoprecipitated independently from partially purified bacterial and LTR $\alpha 3$ nuclear extracts, respectively, using protein A-Sepharoselinked $\mathrm{mAb} 12 \mathrm{CA} 5$ specific for the epitope tag (Zhou et al. 1992). Because holo-eTFIID was purified from the phosphocellulose D fraction (see Materials and methods), it was separated from the TBP-containing complex involved in transcription by RNA polymerase III. After extensive washing in high salt, immobilized reTBP and holo-eTFIID were incubated independently with ${ }^{35} \mathrm{~S}$-labeled large E1A protein that had been translated in a rabbit reticulocyte lysate programmed with the adenovirus $13 \mathrm{~S}$ mRNA. As a control, an equivalent volume of mAb 12CA5 affinity resin itself was incubated with labeled E1A protein. After a second wash, the $12 \mathrm{CA} 5 \mathrm{col}$ umns were eluted with an excess of synthetic epitope peptide to recover the reTBP-E1A and holo-eTFIID-E1A complexes. Duplicate sets of sample aliquots from the column eluates were then subjected to SDS-PAGE. Aliquot volumes were adjusted so that equivalent amounts 
of eTBP were present in the reTBP and holo-eTFIID samples. One set of the samples was processed by quantitative Western blot analysis to ensure that equivalent amounts of eTBP were present in each sample (Fig. 3B, lanes 4,5 ), whereas the remaining sample set was analyzed by fluorography to determine the amount of ${ }^{35} \mathrm{~S}$ labeled E1A protein bound to reTBP and holo-eTFIID. The input large E1A protein migrates as two major species of $\sim 45$ and $38 \mathrm{kD}$ attributable to alternative phosphorylations of the protein (Fig. 3A, lane 2). Little E1A was bound and eluted from the control 12CA5 column (Fig. 3A, lane 3). However, ElA protein was bound and eluted from the 12CA5 columns containing reTBP and holo-eTFIID. On a per TBP molecule basis, E1A bound reTBP and holo-eTFIID to a similar extent (Fig. 3A,B, lanes 4,5). This result indicates that the surface on TBP recognized by E1A is available for interaction in holoTFIID and that TAFs do not affect the binding of E1A to TBP significantly.

These protein-binding experiments were performed using the intact large E1A protein translated in vitro from the adenovirus E1A 13S mRNA. In addition to the $13 \mathrm{~S}$ mRNA, an alternatively spliced 12S mRNA is expressed from the E1A gene region during the early phase of adenovirus infection (Flint and Shenk 1989). The small E1A protein translated from the $12 \mathrm{~S}$ mRNA is identical to the large ElA protein except for the deletion of most of CR 3. We therefore confirmed that the surface on E1A principally responsible for its association with holo-eTFIID was CR 3 by testing the ability of the 12Sencoded small E1A protein to bind holo-eTFIID.

Holo-eTFIID was immunoprecipitated from the phosphocellulose D fraction of LTR $\alpha 3$ cell nuclear extract using a mAb 12CA5 column, as described above. The resultant 12CA5-holo-eTFIID column was then divided into two equivalent aliquots; one was incubated with ${ }^{35}$ S-labeled small E1A protein (translated in vitro from the E1A $12 S$ mRNA|, and the other was incubated with ${ }^{35} \mathrm{~S}$-labeled large E1A protein (translated in vitro from the E1A 13 S mRNA). After washing, holo-eTFIID-E1A complexes were eluted from each column with synthetic epitope peptide. A greater amount of large E1A protein was bound by holo-eTFIID than small ElA protein (Fig. 4 , cf. lanes 7 and 5). This result demonstrates that holoeTFIID binds E1A CR3.

It was possible that the interaction of E1A with holoeTFIID observed in these experiments might not be through interactions with TBP but, rather, through novel interactions with TAFs in the holo-eTFIID complex. To test this possiblity we asked whether excess recombinant TBP would block the binding of E1A to the holoeTFIID column by competing with holo-TFIID for the E1A-binding region. rTBP completely blocked binding of the large ElA protein (Fig. 4, cf. lanes 8 and 9). This result argues strongly that E1A binds directly to TBP present in the holo-TFIID complex, although it does not rule out the possibility that E1A might make additional contacts with one or more TAFs.

To corroborate the conclusion that holo-TFIID binds ElA, we performed a reciprocal binding experiment. An
A

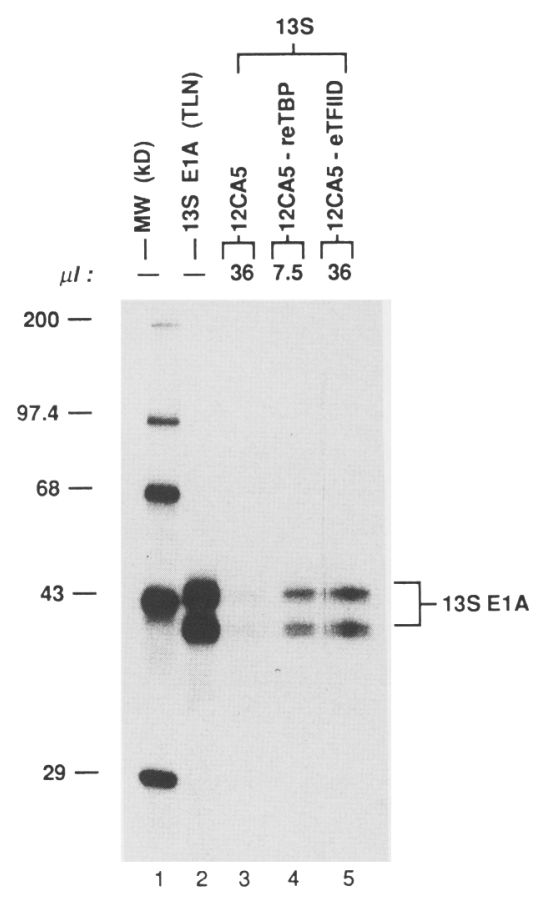

B

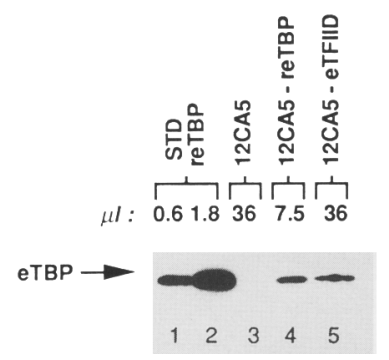

Figure 3. reTBP and holo-eTFID bind ElA to a similar extent. (A) reTBP and holo-eTFIID were immunoprecipitated independently from partially purified bacterial and LTR $\alpha 3$ nuclear extracts, respectively, using a mAb $12 \mathrm{CA} 5$ affinity column as described in Materials and methods. Immobilized reTBP and holoeTFIID and, as a negative control, an equivalent volume of the mAb 12 CA5 affinity resin itself were incubated independently with ${ }^{35}$-labeled large E1A protein translated in vitro in a rabbit reticulocyte lysate from the adenovirus E1A 13 S mRNA. After extensive washing, protein A beads were eluted with the HAl peptide, and the eluate was analyzed by electrophoresis in an SDS-10\% polyacrylamide gel and subsequent fluorography. (Lane 1) molecular mass standards, with the sizes (in kD) indicated at left; (lane 2) A fraction of the ${ }^{35} \mathrm{~S}$-labeled in vitro-translated large E1A protein used in the binding assays; (lane 3) $36 \mu \mathrm{l}$ of eluate from the control 12CA5 affinity column; (lane 4) $7.5 \mu \mathrm{l}$ of eluate from the 12CA5-reTBP column; (lane 5) $36 \mu$ l of eluate from the 12CA5-holo-eTFIID column. The position of the heterogenously migrating $13 \mathrm{~S}$ mRNA-encoded large ElA protein is indicated at right. $(B)$ Quantitative Western blot analysis of aliquots of the column eluates analyzed in $A$ using mAb $12 \mathrm{CA} 5$ specific for eTBP, demonstrating that approximately equivalent amounts of eTBP are present in each sample aliquot of the eluates. Lanes 1 and 2 contain two different concentrations of reTBP (purified from engineered E. coli), which serve as standards. Lanes 3-5 are as in A. 


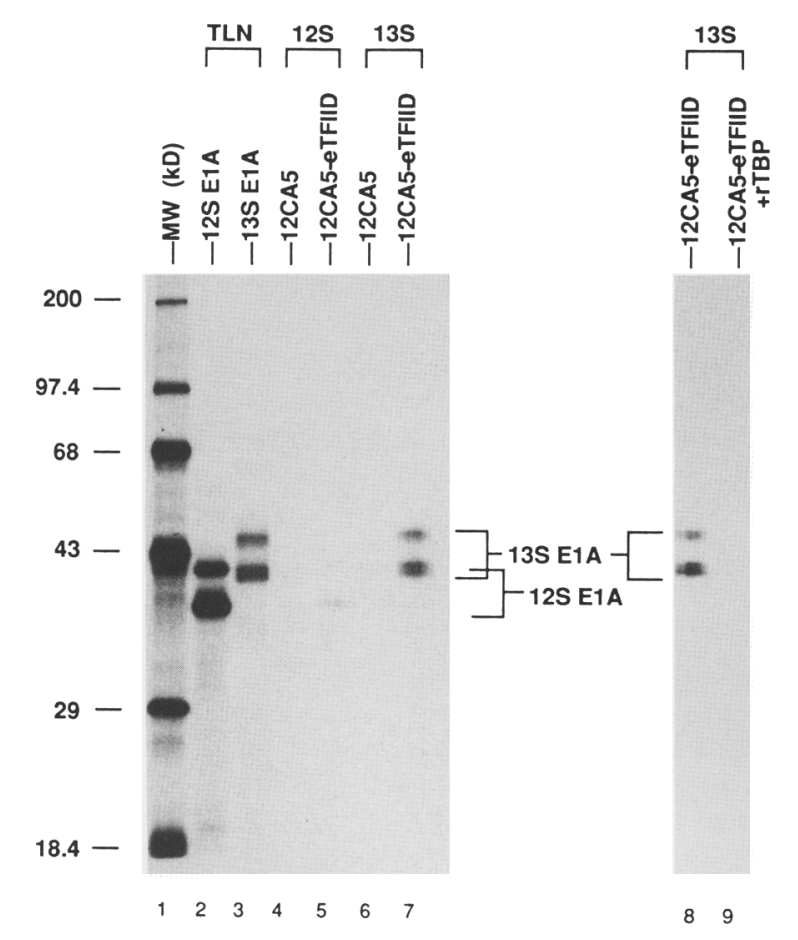

Figure 4. E1A CR 3 is principally responsible for binding the TBP subunit in holo-eTFIID. Holo-eTFIID was immunoprecipitated from partially purified LTR $\alpha 3$ cell nuclear extract using a $\mathrm{mAb} 12 \mathrm{CA} 5$ affinity column as described in the legend to Fig. 3. (Lanes 1-7) Equivalent aliquots of the mAb 12CA5 affinity resin containing immobilized holo-eTFIID or, as a negative control, $\mathrm{mAb} 12 \mathrm{CA} 5$ affinity resin itself were incubated with either ${ }^{35} \mathrm{~S}$ labeled small ElA protein translated in vitro from the adenovirus $12 \mathrm{~S}$ mRNA or ${ }^{35} \mathrm{~S}$-labeled large E1A protein translated in vitro from the adenovirus $13 \mathrm{~S}$ mRNA. After extensive washing, the mAb 12CA5 affinity columns were eluted with the HAl peptide and analyzed by electrophoresis and fluorography as described in the legend to Fig. 3. (Lane 1) Molecular mass standards, with the sizes (in $\mathrm{kD}$ ) indicated at left; (lanes 2,3) equal fractions of the ${ }^{35} \mathrm{~S}$-labeled in vitro translated small $(12 \mathrm{~S})$ and large (13S) E1A proteins used in the binding assays; (lanes 4,6) $18 \mu \mathrm{l}$ of eluate from the control mAb $12 \mathrm{CA} 5$ affinity columns incubated with ${ }^{35} \mathrm{~S}$-labeled small and large E1A proteins, respectively; (lanes 5,7) $18 \mu \mathrm{l}$ of eluate from the 12CA5-holo-eTFIID columns incubated with ${ }^{35} \mathrm{~S}$-labeled small and large E1A proteins, respectively; (lanes 8,9 ) equivalent aliquots of the $\mathrm{mAb}$ $12 \mathrm{CA} 5$ affinity resin containing immobilized holo-eTFIID were incubated with equivalent amounts of ${ }^{35} \mathrm{~S}$-labeled large E1A protein. (Lane 8) Eluate $(18 \mu \mathrm{l})$ from one 12CA5-holo-eTFIID column incubated with ${ }^{35} \mathrm{~S}$-labeled large E1A protein only; (lane 9) $18 \mu \mathrm{l}$ of eluate from a second 12CA5-holo-eTFIID column incubated with ${ }^{35} \mathrm{~S}$-labeled large E1A protein plus $\mathrm{rTBP}$ present in a fourfold molar excess over the amount of TBP protein immobilized on the 12CA5-holo-eTFIID column.

affinity column containing immobilized large E1A protein was prepared and tested for its ability to bind intact holo-eTFIID. This type of analysis also permitted us to address the question of whether or not TAFs are displaced from holo-TFIID when it binds to E1A. Large E1A protein expressed at a high level from a vaccinia virus vector (Lee et al. 1991) was bound to mAb M73, which had been covalently linked to protein A-Sepharose. M73 binds an epitope in the region of the large E1A protein carboxy-terminal to the activation domain of CR 3 (Harlow et al. 1985). A control column consisted of an equivalent volume of the mAb M73 affinity resin itself without bound E1A protein. The ${ }^{32} \mathrm{P}$-labeled holo-eTFIID was generated in vitro by incubation of the phosphocellulose D fraction from LTR $\alpha 3$ cells with $\left[\gamma^{-32}\right.$ P]ATP followed by subsequent immunopurification of the holo-eTFIID complex from the $\mathrm{D}$ fraction as described previously. Endogenous kinase activity within the phosphocellulose $\mathrm{D}$ fraction was sufficient to label all of the TAFs in the holo-eTFIID complex to varying specific activities (Fig. 5, lane 2; data not shown). Epitope-tagged TBP was also labeled, albeit weakly. TAFs 250, 125, 95, 78, 50, 30, and 28 are all components of the high-molecular-mass $17 \mathrm{~S}$ holo-TFIID complex involved in activated transcription (Zhou et al. 1992). TAF70 resides in a separate low-mo-

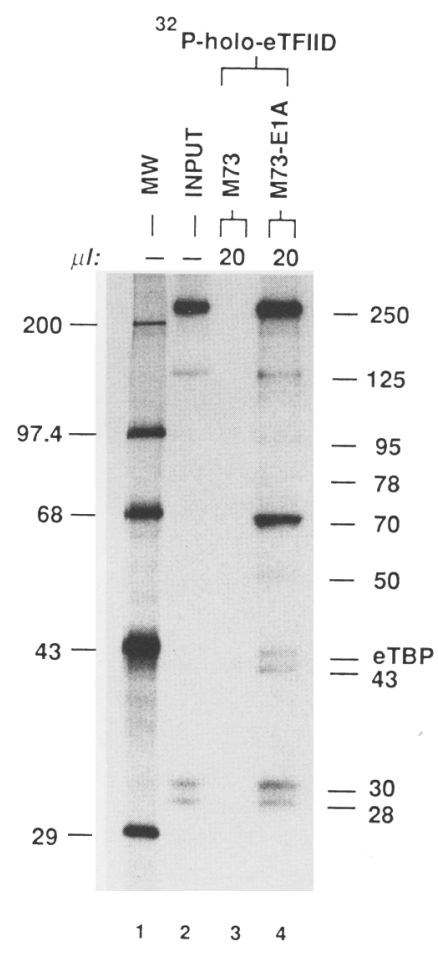

Figure 5. E1A binds intact holo-eTFIID. Large E1A protein expressed at a high level from a vaccinia virus vector was bound to an mAb M73 affinity column, as described in Materials and methods. Immobilized E1A and, as a negative control, an equivalent volume of the $\mathrm{mAb} M 73$ affinity resin itself were independently incubated with ${ }^{32} \mathrm{P}$-labeled immunopurified holoeTFIID. After extensive washing, protein A beads were eluted with SDS and analyzed by electrophoresis in an SDS-10\% polyacrylamide gel and subsequent autoradiography. (Lane 1) Molecular mass standards, with sizes (in $\mathrm{kD}$ ) indicated at left; (lane 2) $7.5 \%$ of the ${ }^{32} \mathrm{P}$-labeled holo-eTFIID used in the binding assays; (lane 3) $20 \mu$ l of eluate from the control M73 affinity column; (lane $420 \mu$ l of eluate from the M73-E1A affinity column. The positions of individual TAFs (with sizes in $\mathrm{kD}$ ) present in the input holo-eTFIID complex and in the eluate recovered from the E1A affinity column are indicated at right. 
lecular-mass $4 \mathrm{~S}$ complex with TBP, which has not been reported to have transcriptional activity (Zhou et al. 1992). TAF43 was not visualized previously (Zhou et al. 1992), and it is not known at present where TAF43 sediments during sedimentation velocity centrifugation of holo-TFIID.

Equal aliquots of labeled holo-eTFIID were incubated with the ElA and control affinity resins in RIPA buffer containing detergents and $150 \mathrm{~mm} \mathrm{NaCl}$ to inhibit nonspecific interactions. After extensive washing with RIPA buffer and $0.8 \mathrm{M} \mathrm{LiCl}$, the affinity resins were eluted with SDS and the eluate was analyzed by SDS-PAGE to determine whether intact holo-eTFIID was bound by E1A. No detectable holo-eTFIID was bound and eluted from the control M73 column (Fig. 5, lane 3). However, holoeTFIID was bound and eluted from the M73 column containing E1A (Fig. 5, lane 4). For those TAFs present in the high-molecular-mass 17S holo-eTFIID complex (i.e., TAFs $250,125,95,78,50,30$, and 28), the ratio of labeled TAFs recovered from the $M 73$ column containing immobilized E1A was similar to the ratio of labeled TAFs present in the input holo-eTFIID complex (Fig. 5, cf. lanes 4 and 2). These results confirm that holo-eTFIID can bind to E1A. Moreover, the results indicate that none of the ${ }^{32} \mathrm{P}$-labeled TAFs are displaced when E1A binds to holo-eTFIID. The low-molecular-mass TAF70TBP complex of unknown function appears to bind E1A more readily than the high-molecular-mass $17 \mathrm{~S}$ holoeTFIID complex, as TAF70 was reproducibly enriched in the eluate from the E1A column (Fig. 5, cf. lanes 4 and 2). The significance of this observation is presently unknown. TAF43, which was also enriched in the eluate from the E1A affinity column, may reside in a complex with TAF70 and TBP, although this possibility remains to be established definitively. Nonetheless, these results clearly establish that E1A can bind to the holo-TFIID complex required for activated transcription. In an effort to assess the functional significance of this interaction, we turned to the ElA-responsive in vitro transcription system described in the previous section.

\section{High concentrations of E1A CR 3 inhibit \\ E1A-dependent and E1A-independent transcription in vitro}

It has been demonstrated previously by others that overexpression of ElA in mammalian cells leads to an inhibition of transcription stimulated by both itself and certain other transcriptional activators (Martin et al. 1990). This phenomenon, termed squelching, is believed to result from titration by excess ElA of its cellular target (Ptashne 1988; Martin et al. 1990). During extended titrations of GAL4-E1A, we observed that this phenomenon could be reproduced in vitro. Figure 6 shows representative titrations of GAL4-E1A and GAL4-E1A 171A/ $174 \mathrm{~A}$ in reconstituted transcription reactions on the $\mathrm{pG}_{5} \mathrm{E} 1 \mathrm{BCAT}$ (Lillie and Green 1989) reporter template. Addition of increasing amounts of GAL4-E1A resulted in a gradual stimulation of transcription until a maximum was observed at $\sim 0.15$ pmole of input activator

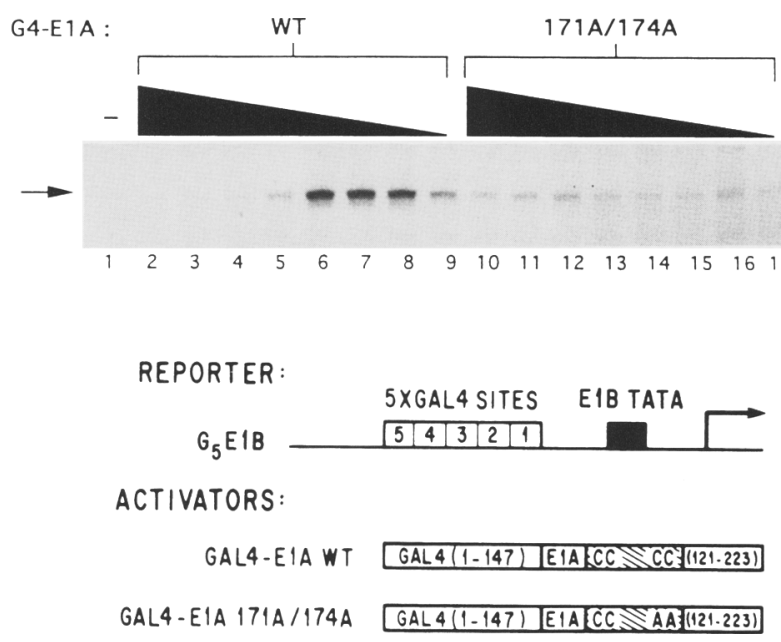

Figure 6. High concentrations of GAL4-E1A inhibit GAL4ElA-mediated transcriptional stimulation in vitro. Primer extension analysis of transcripts synthesized in vitro from the $\mathrm{pG}_{5}$ E1BCAT (Lillie and Green 1989) reporter template. Transcription reactions were performed in a system reconstituted from partially purified general factors as described in Materials and methods in the absence (lane 1) or in the presence of decreasing concentrations of GAL4-E1A (lanes 2-9) or GAL4-E1A 171A/174A (lanes 10-17). The amount of each activator added to in vitro transcription reactions corresponds to 6.0 pmole (lanes 2,10), 4.8 pmole (lanes 3,11), 2.4 pmole (lanes 4,12), 1.2 pmole (lanes 5,13 ), 0.6 pmole (lanes 6,14), 0.3 pmole (lanes 7,15), 0.15 pmole (lanes 8,16 ), and 0.06 pmole (lanes 9,17 ). The position of the specific transcript is indicated by the arrow at left. Schematic diagrams of the $\mathrm{pG}_{5} \mathrm{E} 1 \mathrm{BCAT}$ reporter template /transcription initiation site designated by right-angled arrow) and the activators used are depicted below.

(Fig. 6, lane 8). This level of transcription was generally maintained as the amount of input GAL4-E1A was increased fourfold to 0.6 pmole (Fig. 6, lanes 7 and 6, respectively). Beyond 0.6 pmole of input activator protein, transcription levels declined sharply; a further twofold increase in the amount of input GAL4-E1A, to 1.2 pmole, effectively reduced transcription to near basal levels (Fig. 6, lane 5). The surprisingly abrupt decrease in the level of transcription with a twofold increase in GAL4-E1A concentration from 0.6 to 1.2 pmole was reproducibly observed. This is interpreted as diagramed in Figure 7. At low concentrations of GAL4-E1A, the activation domain of a GAL4-E1A molecule bound to the promoter region interacts with a critical target molecule required for activated transcription (Fig. 7, top). At high concentrations of GAL4-E1A (Fig. 7, middle), target molecules are titrated by excess GAL4-E1A not bound to the promoter so that few target molecules are available to interact with the GAL4-E1A molecules bound to the promoter being assayed.

In contrast to the pattern of transcriptional modulation observed with increasing concentrations of GAL4 E1A, the level of transcription observed with GAL4-E1A $171 \mathrm{~A} / 174 \mathrm{~A}$ changed very little through this same concentration range (see Fig. 6, lanes 10-17). This observa- 
activated transcription

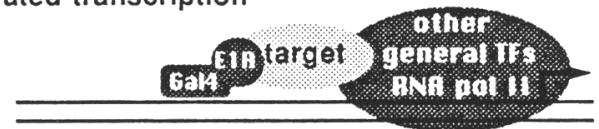

squelched activation

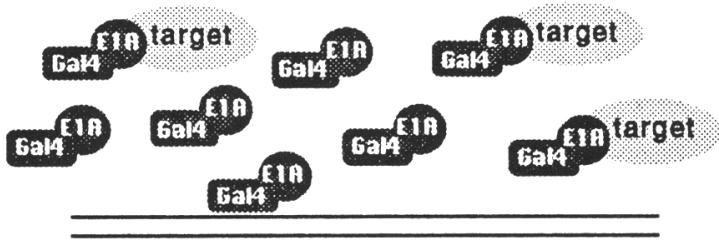

rescue of squelched activation by addition of target

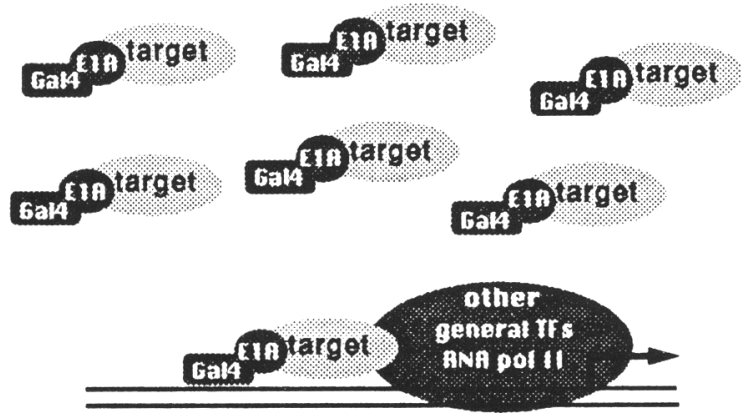

Figure 7. Model for transcriptional squelching in vitro by excess GAL4-E1A and subsequent rescue of squelching by exogenous addition of the functional target of GAL4-E1A. (Top) At optimal concentrations of GAL4-E1A (when all GAL4 DNAbinding sites have been occupied) the activation domain of a GAL4-E1A molecule bound to the test promoter interacts with a critical target molecule required for activated transcription. (Middle) At high concentrations of GAL4-E1A, target molecules are sequestered by excess GAL4-E1A molecules not bound to the test promoter; therefore, few target molecules are available for interaction with GAL4-E1A bound to the test promoter. (Bottom) Exogenous addition of target molecules in excess of the amount that can be titrated efficiently by GAL4-ElA molecules not bound to the test promoter restores activated transcription by ensuring that target molecules are available for interaction with GAL4-E1A bound to the test promoter.

tion suggests that transcriptional inhibition mediated by high concentrations of CR 3 requires an intact activation domain. In an effort to assess more conclusively whether an intact activation domain is required for transcriptional inhibition by CR 3, we tested the ability of GAL4E1A and GAL4-E1A 171A/174A to function as inhibitors from a heterologous transcription unit with higher intrinsic activity than the $\mathrm{pG}_{5} \mathrm{E} 1 \mathrm{BCAT}$ template.

The adenovirus E1B core promoter is relatively simple in structure, essentially consisting of a single Sp1-binding site (GC box) positioned 8 bp upstream of a TATA box (Wu et al. 1987; Spector et al. 1993; Fig. 8). In a system reconstituted from partially purified general fac- tors, the level of transcription from the E1B promoter is relatively high, owing to the presence of endogenous $\mathrm{Spl}$ in one or more of the general transcription factor fractions (Fig. 8, lane 1). This conclusion is based on the observation that mutation of the Spl-binding site within the ElB promoter reduces transcription considerably from an otherwise identical promoter template in the same reconstituted transcription system (data not shown). The addition of 7.5 pmoles of GAL4-E1A to the reconstituted transcription reaction, an amount of activator sufficient to inhibit its own activated transcription completely, significantly reduced Spl-dependent transcription from the E1B promoter (Fig. 8, lane 3). We interpret this observation to imply that excess GAL4-E1A is sequestering a component of the general transcriptional apparatus that is required for transcription from the core E1B promoter. Of import is the fact that addition of an equivalent number of pmoles of GAL4-E1A 171A/174A inhibited transcription only very slightly from the E1B promoter (Fig. 8, lanes 4,5). Collectively, these results demonstrate that activation and inhibition of transcription mediated by GAL4-E1A are affected similarly by mutations in the activation domain of CR 3 . It is likely, therefore, that these two processes are related and involve an interaction of CR 3 with a common target in the general transcriptional apparatus.

\section{Holo-eTFIID reverses transcriptional inhibition mediated by high concentrations of GAL4-E1A}

If squelching occurs by the titration of a target factor required for activation, as depicted in Figure 7 (middle),

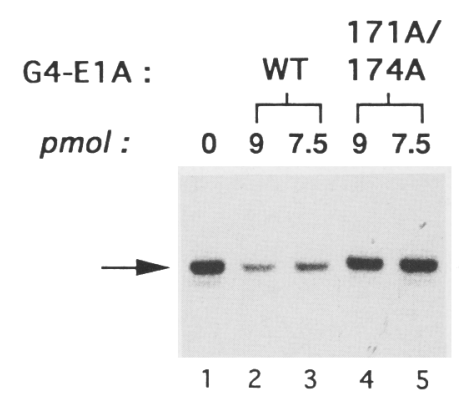

REPORTER :

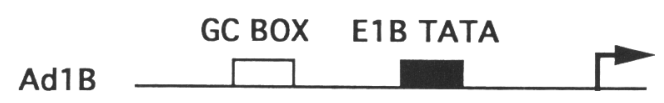

Figure 8. High concentrations of GAL4-E1A inhibit transcription from the adenovirus E1B core promoter. Primer extension analysis of transcripts synthesized in vitro from the pAdlB (Schmidt et al. 1989) reporter template. Transcription reactions were performed in a system reconstituted from partially purified general factors as described in Materials and methods in the absence (lane 1) of GAL4-E1A or in the presence of the indicated number of pmoles of GAL4-E1A (lanes 2,3) or GAL4-E1A 171 A/174A (lanes 4,5). The position of the specific transcript is indicated by the arrow at left. A schematic diagram of the pAdlB reporter template (transcription initiation site designated by right-angled arrow) is depicted below. 
then the identification of an activity that restores activated transcription to an inhibited reaction should establish that activity as a functional target of CR 3 (Fig. 7, bottom). To identify this activity, we tested the ability of each transcription factor fraction in our reconstituted system to individually reverse transcriptional inhibition by excess GAL4-E1A.

Under standard in vitro reaction conditions, the addition of 0.6 pmoles of GAL4-E1A resulted in a significant stimulation of basal level transcription (Fig. 9A, cf. lane 2 and lane 1). The addition of 3.6 pmoles of GAL4-ElA inhibited activated transcription completely (Fig. 9A, cf. lanes 3 and 2). Under these conditions of inhibited transcription (i.e., 3.6 pmoles of input GAL4-E1A) neither the addition of excess TFIIA, rTFIIB, nor TFIIE/F and RNA polymerase II was sufficient to restore activated transcription (Fig. 9A, lanes 4-6). Addition of these excess factors had no significant effect on transcription in the presence of 0.6 pmole of GAL4-ElA (data not shown), demonstrating that these factor preparations did not contain inhibitors that might have prevented us from observing rescue of the squelched reactions. In contrast, under identical conditions, the addition of purified holo-eTFIID efficiently reversed transcriptional inhibition mediated by excess GAL4-E1A (Fig. 9A, lanes 7-9). Quantitative Western blot analysis was used to estimate the amount of TBP present in both the partially purified TFIID fraction $(2 \mu l)$ initially used to reconstitute transcription with the other general factors and the purified holo-eTFIID complex added back to inhibited reactions (Fig. 9B, lanes 1-6). When added to transcription reactions inhibited by 3.6 pmoles of GAL4-E1A, an amount of holo-eTFIID equivalent to twice the amount of partially purified TFIID initially present restored activated transcription to twice the level observed with 0.6 pmole of GAL4-E1A (Fig. 9A, cf. lanes 7 and 2; Fig. 9B, cf. lanes 6 and 2). We also noted that an increase in the amount of input GAL4-E1A used to inhibit transcription beyond 3.6 pmoles resulted in a corresponding requirement for more holo-eTFIID to reverse inhibition (data not shown). These observations suggest that GAL4-E1A and holoeTFIID interact in a strict stoichiometric fashion. In this experiment the amount of TFIIA, rTFIIB, and TFIE/F and RNA polymerase II fractions added back to inhibited reactions (i.e., 4,8 , and $10 \mu l$, respectively) represented four times the amount of each fraction initially used to reconstitute transcription in vitro. Each of these fractions has been tested for its respective ability to rescue inhibited transcription over a range of concentrations corresponding to from one-half to four times the amount used initially to reconstitute transcription. At none of the concentrations tested did any of these general transcription factor fractions rescue the inhibition of transcription mediated by excess GAL4-E1A. reTBP also failed to rescue inhibited transcription (Fig. 9A, lanes 10-12). Although we expect that reTBP competed with holo-TFIID present in the partially purified TFIID-containing fraction for binding to E1A, reTBP would also be expected to compete with holo-TFIID for binding to the TATA box. Because reTBP can only support basal and
A

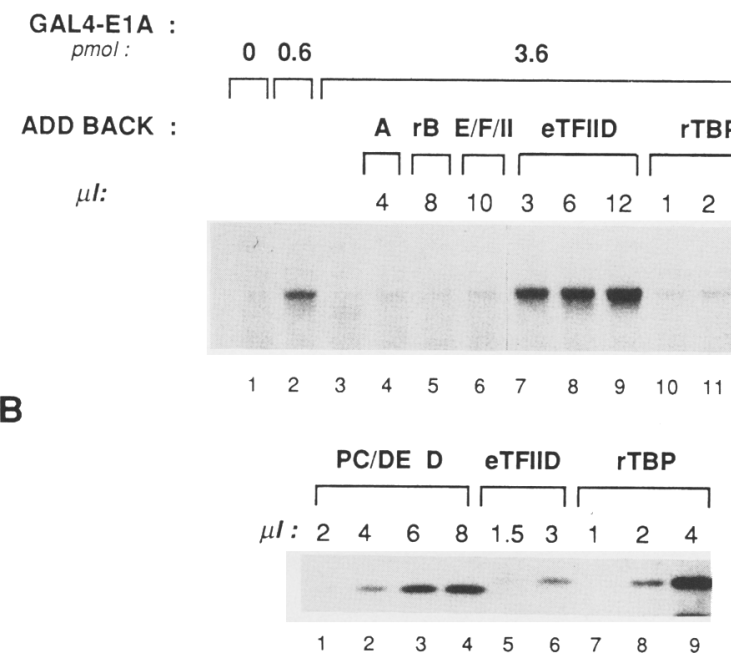

Figure 9. Holo-eTFIID reverses transcriptional inhibition mediated by high concentrations of GAL4-E1A. $(A)$ Primer extension analysis of transcripts synthesized in vitro from the $\mathrm{pG}_{5} \mathrm{E} 1 \mathrm{BCAT}$ reporter template. Transcription reactions were performed in a system reconstituted from partially purified general factors, as described in Materials and methods, in the absence (lane 1) or in the presence of 0.6 pmole (lane 2) or 3.6 pmoles (lanes 3-12) of GAL4-E1A. The reaction shown in lane 3 was not supplemented with additional transcription factor fractions. For the reactions shown in lanes $4-6$, the indicated amount of the TFIIA, rTFIIB, or TFIIE/F and RNA polymerase II fractions were added in excess of the amount of each fraction used initially to reconstitute transcription /described in Materials and methods). For the reactions shown in lanes $7-12$, the indicated amounts of affinity-purified holo-eTFIID and reTBP were added to transcription reactions reconstituted with each of the general factors. The unsupplemented reactions in lanes 1-3 contained $1 \mu$ l of TFIIA fraction, $2 \mu$ l of rTFIIB, $2.5 \mu$ l of TFIIE/ F-RNA polymerase II fraction, and $2 \mu l$ of TFIID fraction partially purified by successive phosphocellulose (PC) and DEAESepharose (DE) chromatography. (B) Quantitative Western blot analysis of TBP using a polyclonal rabbit antiserum raised against rTBP (Lee et al. 1991). The indicated amounts of the partially purified HeLa cell TFIID fraction initially used to reconstitute in vitro transcription with each of the other general factors (lanes 1-4), holo-eTFIID affinity purified from LTR $\alpha 3$ cell D fraction (lanes 5,6), and reTBP affinity purified from engineered $E$. coli (lanes 7-9) were analyzed by electrophoresis in an SDS- $10 \%$ polyacrylamide gel and Western blotting. The slight difference in electrophoretic migration between endogenous TBP present in the partially purified HeLa cell TFIID fraction (lanes 1-4) and eTBP (lanes 5-9) derives from the presence of the epitope tag on $\mathrm{TTBP}$.

not activated transcription, only the low basal level of transcription observed (lanes 10-12) would be expected.

We considered the possibility that this analysis merely identified the limiting factor required for activated transcription, not necessarily the factor directly titrated by binding to the ElA activation domain. To test this possibility, we established in vitro conditions under which rTFIIB was limiting for transcription. Under our standard 
conditions for reconstituted transcription, a fivefold reduction in the amount of rTFIIB reduced the level of GAL4-E1A-activated transcription by a factor of 2 . At this concentration of rTFIIB, addition of sixfold more GAL4-E1A inhibited transcription as observed previously. Under these conditions of inhibited transcription, the addition of 2-, 5-, or 10-fold more rTFIIB failed to restore activated transcription (data not shown). This result demonstrates that transcriptional inhibition mediated by excess GAL4-E1A cannot be reversed simply by the addition of a component that was initially limiting in the reconstituted transcription system. The result underscores the specific ability of holo-eTFIID to perform this function. Thus, from among the component activities that collectively reconstitute GAL4-E1A-activated transcription in vitro, holo-eTFIID alone is singularly capable of reversing transcriptional inhibition brought about by high concentrations of GAL4-E1A. This result (Fig. 9A), plus the observation that CR 3 binds to holoTFIID directly (Figs. 3-5), leads us to conclude that holoTFIID is a functional target of E1A CR 3.

\section{Discussion}

Identification of cellular targets through which transcriptional activators function is a requisite first step toward understanding the molecular mechanism by which these regulatory proteins stimulate transcription. In this paper we present biochemical evidence that the ElA activation domain stimulates transcription through a direct interaction with holo-TFIID, the multisubunit protein complex consisting of TBP and TAFs required for activated transcription by RNA polymerase II. We observed that E1A binds stably and specifically to purified holo-eTFIID immobilized on protein A-Sepharose; this interaction requires the ElA activation domain and is mediated through the TBP subunit of holo-TFIID. Similarly, we observed that holo-TFIID bound to immobilized E1A protein. In this experiment (Fig. 5), holo-TFIID was labeled in vitro by a procedure that labeled all of the characterized TFIID TAFs present in the high-molecularmass $17 \mathrm{~S}$ holo-TFIID complex required for activated transcription. All of these bound to the E1 A column indicating that they are not displaced from holo-TFIID when it binds to E1A. In addition, a $70-\mathrm{kD}$ polypeptide associated with TBP in a $4 \mathrm{~S}$ complex of unknown function (Zhou et al. 1992) also bound to E1A. The significance of this interaction is presently unclear.

In an effort to assess the functional significance of the interaction of E1A with holo-TFIID, we established an E1A-responsive in vitro transcription system reconstituted from partially purified general transcription factors and RNA polymerase II. Addition of excess GAL4-E1A to this system inhibited transcription by sequestering a target factor required for GAL4-E1A-mediated activation. From among the component activities that collectively reconstitute GAL4-E1A-responsive transcription in this system, only holo-TFIID was capable of reversing the inhibition of transcription mediated by excess
GAL4-E1A. On this basis, we conclude that holo-TFIID is a functional target of the ElA activation domain.

A growing body of biochemical and genetic evidence has lent support to a model for E1A trans-activation in which CR 3 binds to at least two distinct cellular targets through the amino-terminal finger region and the carboxyl region. It has been proposed that the carboxyl region directs ElA to a target transcription unit by interacting with cellular promoter-bound sequence-specific transcription factors, whereas the finger region stimulates transcription by interacting with a component of the general transcription machinery (Lillie and Green 1989). Several lines of experimental evidence have suggested that TFIID is the general transcription factor targeted by the finger region of CR 3 . Initially, the observation that the transcriptional activity of a partially purified TFIID fraction from HeLa cells was increased by adenovirus infection implicated this general transcription factor as a potential mediator of E1A trans-activation (Leong et al. 1988). Subsequently, it was demonstrated that EIA CR 3 binds in vitro specifically and stably to the isolated TBP subunit of TFIID (Horikoshi et al. 1991; Lee et al. 1991). Ricciardi and colleagues engineered conservative substitutions at each of the 49 amino acid residues of CR 3 and tested these mutants for trans-activation function in vivo (Webster and Ricciardi 1991). Presently, these same mutants have been tested for their ability to bind TBP in vitro. In general, there is an excellent correlation between the effects of mutations in the finger region on TBP binding in vitro and on transactivation in vivo (J. Geisberg, W. Lee, A.J. Berk, and R.P. Ricciardi, unpubl.). Collectively, these observations provided compelling correlative evidence that E1A stimulates transcription, in part, through an interaction with TBP. Our results support this model and provide the first direct functional evidence that trans-activation is mediated through a direct physical association between the ElA activation domain and TBP in the holo-TFIID complex.

The observation that E1A binds holo-TFIID through the TBP subunit of the latter has several implications that bear on the mechanism of E1A trans-activation. First, the surface on TBP recognized by E1A must be accessible for interaction in the holo-TFIID complex, despite the simultaneous association of TBP with at least eight TAFs having a collective estimated mass of $\sim 700$ $\mathrm{kD}$. Knowledge of the residues on TBP required for E1A binding coupled with data derived from both the crystal structure of an Arabidopsis TBP and promoter-binding studies with holo-TFIID suggest a model for how TBP in holo-TFIID might be available for interaction with E1A. in vitro-binding analyses mapped the site on TBP bound by E1A to a 51-residue region from the conserved core domain of TBP that includes a repeat of basic amino acids positioned between the homologous direct repeats (Lee et al. 1991). Resolution of the crystal structure of a TBP from Arabidopsis thaliana revealed that this region forms a surface on TBP that would be readily available for interactions with regulatory proteins such as E1A (Nikolov et al. 1992). Recently, we observed that TBP 
makes direct contacts with at least the two largest TAFs $\left(\mathrm{TAF}_{250}\right.$ and $\left.\mathrm{TAF}_{125}\right)$ in the holo-TFIID complex (Zhou et al. 1993). Others have also reported an interaction between TBP and $\mathrm{TAF}_{250}$ (Takada et al. 1992; Ruppert et al. 1993). A comparison of the DNase I footprint produced by holo-TFIID on the adenovirus major late promoter to the footprint produced by isolated TBP showed identical upstream borders of the two footprints, whereas the downstream footprint produced by holo-TFID extended from the TATA box to a region over and beyond the transcription initiation site (Zhou et al. 1992). On the basis of these observations, we proposed that TBP does not lie at the center of the holo-TFIID complex but, rather, is disposed toward its upstream perimeter. In this configuration, the upstream surface on TBP in holoTFIID would be accessible for interaction with the finger region of E1A CR 3 (Fig. 10). Given its central role in transcription by all three eukaryotic RNA polymerases, it seems likely that multiple proteins compete for overlapping sites on the limited binding surface of TBP. Therefore, the regulation of transcription by E1A and other activator proteins may prove to be a function of their respective abilities to compete for such sites with other activators, inhibitors, polymerase-specific TAFs, and even general transcription factors.

We recently demonstrated that holo-TFIID, but not its isolated TBP subunit, will support efficient transcriptional stimulation by E1A CR 3 in vitro (Zhou et al. 1992). Consistent with this observation, holo-TFIID, but not its isolated TBP subunit, will restore activated transcription efficiently to in vitro reactions inhibited by high concentrations of E1A CR 3 (Fig. 9). These results

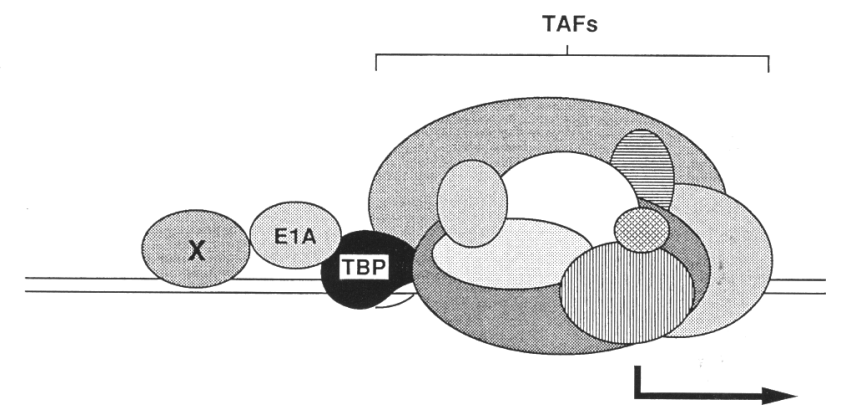

Figure 10. Model for the interaction of E1A CR 3 and holoTFIID. The diagram is drawn to emphasize the interaction of E1A CR 3 with the TBP subunit of holo-TFIID and the interaction of the TBP carboxy-terminal core domain with TAF250 and TAF125 (Zhou et al. 1993). The diagram is drawn for a promoter, such as the adenovirus major late promoter, which makes contacts with TAFs as well as TBP (Zhou et al. 1992). (X) A hypothetical sequence-specific DNA-binding cellular factor that directs E1A to its target promoter through an interaction with the carboxyl domain of E1A CR 3. In this study, (X) represents the DNA-binding domain of GAL4, which has been fused directly to E1A CR 3. The holo-TFIID complex is shown extending downstream from the TATA box on promoter DNA, in accordance with earlier footprinting results (Zhou et al. 1992). The arrangement of TAFs in the complex and the association of specific TAFs with DNA is purely hypothetical. conclusively establish TAFs as critical for E1A-mediated trans-activation, an observation consistent with the demonstrated requirement for all activators tested thus far (Pugh and Tjian 1992; Zhou et al. 1992). We do not know presently how TAFs specifically contribute to E1A trans-activation. Although it is clear that E1A CR 3 binds TBP, it remains to be determined whether CR 3 also makes simultaneous contact with one or more TAFs. Protein-blotting experiments with purified holoTFIID and labeled E1A have thus far revealed only the previously observed interaction between E1A and TBP (T.G. Boyer and A.J. Berk, unpubl.). However, the technical limitations of this analysis preclude drawing a definitive conclusion regarding the association of E1A and TAFs. We note, however, that two conservative substitutions within the finger motif of CR 3 generate ElA mutants that bind TBP in vitro but nonetheless are defective for trans-activation in vivo (J. Geisberg, W. Lee, A.J. Berk, and R.P. Ricciardi, unpubl.). These mutations identify amino acids that represent potential surfaces for contacts with another factor or factors, such as TAFs. However, if ElA-TAF interactions occur, they do not contribute significantly to the stability of the E1A-holoTFIID interaction. We found that TAFs neither significantly increased nor decreased the extent of E1A binding to TBP. The situation appears to be different for the interaction between transcription factor $\mathrm{Spl}$ and holoTFIID. Sp1 does not bind directly to TBP (Hagemeier et al. 1993) but, instead, appears to interact with the holoTFIID complex by binding to one or more TAFs (Hoey et al. 1993). In the case of E1A, TAFs probably mediate transcriptional stimulation at a point subsequent to the binding of E1A to holo-TFIID, contributing activator-dependent biochemical activities required to transduce the stimulatory signal from the activator to RNA polymerase II. Further biochemical analysis of the interactions between CR 3 and holo-TFIID should help to clarify this issue and establish the relative contribution of individual TAFs to ElA-mediated trans-activation.

\section{Materials and methods}

In vitro transcription and translation of E1A proteins

All cRNA synthesis was performed according to standard in vitro transcription conditions (Promega). E1A $12 \mathrm{~S}$ and $13 S$ cRNAs were transcribed from plasmids BBV-12S and BBV-13S (Lee et al. 1991). The ${ }^{35}$ S-labeled E1A proteins were synthesized according to a standard in vitro translation protocol (Promega) by incubating cRNA with rabbit reticulocyte lysate in the presence of Trans ${ }^{35} \mathrm{~S}$-label (ICN).

\section{Affinity purification of reTBP and holo-eTFIID}

Epitope-tagged human TBP (reTBP) was partially purified from engineered $E$. coli as described previously (Lee et al. 1991). HoloeTFIID was partially purified from the human eTBP-expressing LTR $\alpha 3$ cell line as described previously (Zhou et al. 1992). Briefly, LTRa3 cell nuclear extract (Dignam et al. 1983) was fractionated by phosphocellulose chromatography; holo-eTFIID was recovered in the $0.5-1.0 \mathrm{M} \mathrm{KCl} \mathrm{D}$ fraction. Affinity purification of partially purified reTBP and holo-eTFIID was con- 
ducted as described previously (Zhou et al. 1992). Briefly, $1 \mathrm{ml}$ of the undialyzed $\mathrm{D}$ fraction $(\sim 2 \mathrm{mg} / \mathrm{ml})$ was incubated with 0.1 $\mathrm{ml}$ of packed beads of protein A-Sepharose covalently coupled to $\mathrm{mAb} 12 \mathrm{CA} 5$ with rotation at $4^{\circ} \mathrm{C}$ for $8 \mathrm{hr}$. Alternatively, $1 \mathrm{ml}$ of $0.6 \mathrm{M} \mathrm{KCl} \mathrm{D}$ buffer [0.6 M KCl, $20 \mathrm{mM}$ HEPES (pH 7.9), $20 \%$ glycerol, $0.2 \mathrm{~mm}$ EDTA, 0.5 mM DTT, 0.5 mM PMSF] containing partially purified reTBP lan amount roughly equivalent to the amount of eTBP present in $1 \mathrm{ml}$ of the $1.0 \mathrm{M} \mathrm{KCl} \mathrm{D}$ fraction from LTR $\alpha 3$ nuclear extract) was incubated with the coupled protein A-mAb 12 CA5 affinity resin with rotation at $4^{\circ} \mathrm{C}$ for $8 \mathrm{hr}$. The protein A-Sepharose beads were then washed twice for $5 \mathrm{~min}$ each with $0.4 \mathrm{M} \mathrm{KCl} \mathrm{D}$ buffer and twice for $5 \mathrm{~min}$ each with 0.1 $\mathrm{M} \mathrm{KCl} \mathrm{D} \mathrm{buffer.} \mathrm{Subsequently,} \mathrm{the} \mathrm{reTBP} \mathrm{and} \mathrm{the} \mathrm{holo-eTFIID}$ bound to the affinity resin were each eluted in $0.05 \mathrm{ml}$ with the influenza epitope oligopeptide YPYDVPDYA at $1 \mathrm{mg} / \mathrm{ml}$ in 0.1 $\mathrm{M} \mathrm{KCl} \mathrm{D} \mathrm{buffer.}$

\section{mAb $12 C A 5$ bead-binding assay}

reTBP and holo-eTFIID were immunoprecipitated independently from partially purified E. coli and LTR $\alpha 3$ cell nuclear extracts, respectively, and subsequently washed as described above. reTBP and holo-eTFIID immobilized on the coupled protein $\mathrm{A}-\mathrm{mAb} 12 \mathrm{CA} 5$ affinity resin $(0.1 \mathrm{ml}$ packed beads) were then incubated independently at room temperature for $75 \mathrm{~min}$ in $0.5 \mathrm{ml}$ of $0.1 \mathrm{M} \mathrm{KCl} \mathrm{DZ}$ buffer $(0.1 \mathrm{M} \mathrm{KCl} \mathrm{D}$ buffer plus $0.1 \mathrm{~mm}$ $\mathrm{ZnCl}_{2}$ ) that had been supplemented with $0.045 \mathrm{ml}$ of rabbit reticulocyte lysate containing ${ }^{35} \mathrm{~S}$-labeled E1A protein translated in vitro as described above. For the competition-binding experiment shown in Figure 4, rTBP overexpressed in and purified from $E$. coli (Lee et al. 1991) was added concomitantly with ${ }^{35} \mathrm{~S}$-labeled E1A protein. The amount of rTBP added to incubation reactions represented fourfold more TBP protein than the amount of eTBP immobilized on the 12CA5-holo-eTFIID column as determined by quantitative Western blot analysis using a rabbit polyclonal antiserum directed against human TBP (Lee et al. 1991). The protein A-Sepharose beads were then washed four times for $5 \mathrm{~min}$ each with $0.1 \mathrm{M} \mathrm{KCl} \mathrm{DZ}$ buffer and subsequently eluted in $0.05 \mathrm{ml}$ with the influenza epitope oligopeptide at $1 \mathrm{mg} / \mathrm{ml}$ in $0.1 \mathrm{M} \mathrm{KCl} \mathrm{D}$ buffer as described above. Duplicate sets of sample aliquots from the resulting column eluates were then resolved by electrophoresis in SDS-10\% polyacrylamide gels. One set of samples was subjected to Western blot analysis using mAb $12 \mathrm{CA} 5$ to ensure that approximately equivalent amounts of eTBP were present in each sample. The remaining sample set was subjected to $1 \mathrm{M}$ sodium salicylate fluorography treatment and autoradiography.

\section{Preparation of ${ }^{32}$ P-labeled holo-TFIID}

Approximately $1 \mathrm{ml}$ of undialyzed LTR $\alpha 3$ phosphocellulose D fraction $(\sim 2 \mathrm{mg} / \mathrm{ml})$ was adjusted to $10 \mathrm{mM} \mathrm{MgCl}_{2}$ and then incubated at $30^{\circ} \mathrm{C}$ for $30 \mathrm{~min}$ with $2.5 \mu \mathrm{l}$ of $\left[\gamma^{-32} \mathrm{P}\right] \mathrm{ATP}$ (50 $\mu \mathrm{Ci} / \mu \mathrm{l} ;>3000 \mathrm{Ci} / \mathrm{mmole}$; New England Nuclear). Subsequently, $0.1 \mathrm{ml}$ of packed beads of protein A-Sepharose covalently coupled to mAb $12 \mathrm{CA} 5$ was added and ${ }^{32} \mathrm{P}$-labeled holo-eTFIID was immunoprecipitated as described above. Endogenous kinase activity within the phosphocellulose D fraction was sufficient to label all of the TAFs in the holo-eTFIID complex, including TAF250, which labels to high specific activity, TAFs 125,30 , and 28 , which label to intermediate specific activities, and TAFs $95,78,70,50$, and 43 , which label to low specific activities. eTBP was also labeled to a very low specific activity.

\section{M73 bead-binding assay}

E1A protein was immunoprecipitated from whole-cell extracts of HeLa cells that had been infected as described by Lee et al. (1991) with a recombinant vaccinia virus, VE1A, expressing the large E1A protein. Briefly, HeLa cells on $100-\mathrm{mm}$ plates at $80 \%$ confluency were infected with VElA plus the vaccinia virus recombinant vTF7-3, which expresses T7 RNA polymerase, each at an M.O.I. of 10. At $24 \mathrm{hr}$ postinfection, cells were washed twice in phosphate-buffered saline (PBS) and lysed in $0.45 \mathrm{ml}$ of $10 \mathrm{~S}$ buffer [50 mM HEPES (pH 7.2), $250 \mathrm{~mm} \mathrm{NaCl}$, $0.3 \%$ NP-40, $0.1 \%$ Triton X-100, 0.005\% SDS, $10 \mathrm{mM} \mathrm{NaPO}_{4}$ (pH 7.0) $1 \mathrm{mM} \mathrm{NaF}, 0.1 \mathrm{mM}$ PMSF, and $2.5 \mathrm{mM} \beta$-mercaptoethanol] per $100 \mathrm{~mm}$ plate. The lysate was clarified by centrifugation at $14,000 \mathrm{rpm}$ for $10 \mathrm{~min}$ at $4^{\circ} \mathrm{C}$ in an Eppendorf centrifuge and cleared further by incubation with fixed Staphylococcus aureus. Approximately $0.3 \mathrm{ml}$ of extract was incubated with $0.02 \mathrm{ml}$ of packed beads of protein A-Sepharose covalently coupled to $\mathrm{mAb} M 73$ with rotation at $4^{\circ} \mathrm{C}$ for $3 \mathrm{hr}$. The protein A-Sepharose beads were then washed twice for 5 min each with $10 \mathrm{~S}$ buffer and then twice for $5 \mathrm{~min}$ each with RIPA buffer [10 $\mathrm{mm}$ Tris- $\mathrm{HCl}(\mathrm{pH} 8.0), 150 \mathrm{mM} \mathrm{NaCl}, 1 \% \mathrm{NP}-40,1 \%$ sodium deoxycholate, $1 \mathrm{~mm}$ EDTA, $0.5 \mathrm{mM}$ PMSF, and $2.5 \mathrm{~mm} \beta$-mercaptoethanol] containing $2 \%$ BSA. E1A immobilized on the coupled protein $\mathrm{A}-\mathrm{mAb} \mathrm{M} 73$ affinity resin, and as a negative control, an equivalent volume of the protein A-mAb M73 affinity resin itself was then incubated independently at room temperature for $1.5 \mathrm{hr}$ in $0.2 \mathrm{ml}$ of RIPA buffer containing $2 \%$ BSA that had been supplemented with $0.03 \mathrm{ml}$ of immunoaffinity-purified ${ }^{32} \mathrm{P}$-labeled holo-eTFIID $(\sim 1800 \mathrm{cpm})$ prepared as described above. The protein A-Sepharose beads were then washed four times for 5 min each with RIPA buffer containing $2 \%$ BSA, once for 5 min with $0.8 \mathrm{M} \mathrm{LiCl}$, and once with PBS. The affinity resins were then eluted with Laemmli sample buffer at $90^{\circ} \mathrm{C}$ for $5 \mathrm{~min}$, and the eluate was analyzed by electrophoresis in an SDS-10\% polyacrylamide gel and subsequent autoradiography of the dried gel.

\section{In vitro transcription assays}

The $0.05-\mathrm{ml}$ in vitro transcription reactions performed in unfractionated HeLa cell nuclear extracts contained $20 \mathrm{mM}$ HEPES (pH 7.9), $60 \mathrm{mM} \mathrm{KCl}, 7.5 \mathrm{~mm} \mathrm{MgCl}_{2}, 40 \mathrm{~mm} \beta$-mercaptoethanol, $15 \mu \mathrm{M} \mathrm{ZnCl}, 0.6 \mathrm{~mm}$ ribonucleoside triphosphates, $12 \%$ glycerol, $4 \%$ polyethylene glycol, $120 \mu \mathrm{g}$ of HeLa cell nuclear extract (Dignam et al. 1983), $200 \mathrm{ng}$ of template plasmid $\left[\mathrm{pG}_{5} \mathrm{E} 4 \mathrm{~T}\right.$ (Carey et al. 1990b)l, and either no activator protein or, alternatively, the indicated amounts of GAL4-E1A or GAL4-E1A $171 \mathrm{~A} / 174 \mathrm{~A}$, each purified from engineered $E$. coli as described previously for GAL4-E1A (Zhou et al. 1992). After $60 \mathrm{~min}$ at $30^{\circ} \mathrm{C}$, the reactions were terminated, and the reaction products were analyzed by primer extension as described (Carey et al. 1990b) using primers described in Zhou et al. (1992).

The $0.03-\mathrm{ml}$ in vitro transcription reactions reconstituted from partially purified general factors contained $20 \mathrm{mM}$ HEPES (pH 7.9), $60 \mathrm{mM} \mathrm{KCl}, 7.5 \mathrm{mM} \mathrm{MgCl}_{2}, 40 \mathrm{mM} \beta$-mercaptoethanol, $15 \mu \mathrm{M} \mathrm{ZnCl}_{2}, 0.6 \mathrm{mM}$ ribonucleoside triphosphates, $12 \%$ glycerol, $4 \%$ polyethylene glycol, $6 \mu \mathrm{g}$ fraction TFIIA, $100 \mathrm{ng}$ recombinant TFIIB (rTFIIB), $10 \mu \mathrm{g}$ fraction TFIIE/F and RNA polymerase II, $8 \mu \mathrm{g}$ fraction TFIID, $100 \mathrm{ng}$ of template plasmid (pG ${ }_{5}$ E1BCAT (Lillie and Green 1989) or pAd1B (Schmidt et al. 1989)], and either no activator or, alternatively, the indicated amounts of GAL4-E1A or GAL4-E1A 171A/174A. After 60 min at $30^{\circ} \mathrm{C}$, the reactions were terminated and the reaction products were analyzed by primer extension as described (Schmidt et al. 1989). Add-back experiments were performed 
under conditions identical to those described above except that the indicated amount of each individual transcription factor fraction (TFIIA, rTFIIB, and TFIIE/F and RNA polymerase II) was added in excess of the amount of each fraction described above for a standard reconstituted in vitro transcription reaction. reTBP and holo-eTFIID used in add-back experiments were each immunopurified as described above. Fractions TFIIA, TFIIE/F and RNA polymerase II, and TFIID were purified from HeLa cell nuclear extract by chromatography on phosphocellulose and DEAE-Sepharose as described by Lin and Green (1991). The TFIIA fraction also contains TFIIJ (Cortes et al. 1992). The TFIIE/F and RNA polymerase II fraction also contains TFIIH (Flores et al. 1992). Recombinant TFIIB was purified from engineered E. coli as described by Ha et al. (1991).

\section{Acknowledgments}

We thank Carol Eng for technical assistance, Paul Lieberman and Michael Carey for comments on the manuscript, and members of the Berk laboratory, particularly P. Renee Yew, Qiang Zhou, and Phillipa Shepherd-Mix, for helpful discussions. This work was supported by grant CA 25235 from the National Cancer Institute. T.G.B. received a postdoctoral fellowship from the American Cancer Society.

The publication costs of this article were defrayed in part by payment of page charges. This article must therefore be hereby marked "advertisement" in accordance with 18 USC section 1734 solely to indicate this fact.

\section{References}

Berk, A.J. 1986. Adenovirus promoters and E1A transactivation. Annu. Rev. Genet. 20: 45-79.

Carey, M., J. Leatherwood, and M. Ptashne. 1990a. A potent GAL4 derivative activates transcription at a distance in vitro. Science 247: 710-712.

Carey, M., Y.S. Lin, M.R. Green, and M. Ptashne. 1990b. A mechanism of synergistic activation of a mammalian gene by GAL 4 derivatives. Nature 345: 361-364.

Chaterjee, P.K., M. Bruner, S.J. Flint, and M.L. Harter. 1988. DNA binding properties of an adenovirus 286R E1A protein. EMBO I. 7: 835-841.

Cortes, P., O. Flores, and D. Reinberg. 1992. Factors involved in transcription by mammalian RNA polymerase II: Purification and analysis of transcription factor IIA and identification of transcription factor IIJ. Mol. Cell. Biol. 12: 413-421.

Culp, J.S., L.C. Webster, D.J. Friedman, C.L. Smith, W.-J. Huang, F. Y.-H. Wu, M. Rosenberg, and R.P. Ricciardi. 1988. The 289-amino acid ElA protein of adenovirus binds zinc in a region that is important for trans-activation. Proc. Natl. Acad. Sci. 85: 6450-6454.

Dignam, J.D., R.M. Lebovitz, and R.G. Roeder. 1983. Accurate transcription initiation by RNA polymerase II in a soluble extract from isolated mammalian nuclei. Nucleic Acids Res. 11: $1475-1489$.

Dynlacht, B.D., T. Hoey, and R. Tiian. 1991. Isolation of coactivators associated with the TATA-binding protein that mediate transcriptional activation. Cell 66: 563-576.

Flint, J. and T. Shenk. 1989. Adenovirus E1A protein: Paradigm viral transactivator. Annu. Rev. Genet. 23: 141-161.

Flores, O., H. Lu, and D. Reinberg. 1992. Factors involved in specific transcription initiation by mammalian RNA polymerase II. Identification and characterization of factor IIH. J. Biol. Chem. 267: 2786-2793.

Gill, G. and M. Ptashne. 1988. Negative effect of the transcrip- tional activator GAL4. Nature 334: 721-724.

Ha, I., W.S. Lane, and D. Reinberg. 1991. Cloning of a human gene encoding the general transcription factor IIB. Nature 352: 689-695.

Hagemeier, C., A.J. Bannister, A. Cook, and T. Kouzarides. 1993. The PU.1 activation domain binds RB and TFIID in vitro: $\mathrm{RB}$ shows sequence similarity to TFIID and TFIIB. Proc. Natl. Acad. Sci. 90: 1580-1584.

Harlow, E., B.R. Franza, and C. Schley. 1985. Monoclonal antibodies specific for adenovirus early region $1 \mathrm{~A}$ proteins: Extensive heterogeneity in early region 1 A products. $/$. Virol. 55: 533-546.

Hoey, T., R.O.J. Weinzierl, G. Gill, J.-L. Chen, B.D. Dynlacht, and R. Tjian. 1993. Molecular cloning and functional analysis of Drosophila TAF110 reveals properties expected of coactivators. Cell 72: 247-260.

Horikoshi, N., K.M. Maguire, A. Kralli, E. Maldonado, D. Reinberg, and R. Weinman. 1991. Direct interaction between adenovirus E1A protein and the TATA box-binding transcription factor IID. Proc. Natl. Acad. Sci. 88: 5124-5128.

Ingles, C.J., M. Shales, W.D. Cress, S.J. Triezenberg, and J. Greenblatt. 1991. Reduced binding of TFIID to transcriptionally compromised mutants of VP16. Nature 351: 588-590.

Lee, W.S., C.C. Kao, G.O. Bryant, X. Liu, and A.J. Berk. 1991. Adenovirus E1A activation domain binds the basic repeat in the TATA box transcription factor. Cell 67: 365-376.

Leong, K., L. Brunet, and A.J. Berk. 1988. Factors responsible for the higher transcriptional activity of extracts of adenovirusinfected HeLa cells fractionate with the TATA box transcription factor. Mol. Cell. Biol. 8: 1765-1774.

Lieberman, P.M. and A.J. Berk. 1991. The Zta trans-activator protein stabilizes TFIID association with promoter DNA by direct protein-protein interaction. Genes \& Dev. 5: 24412454.

Lillie, J.W. and M.R. Green. 1989. Transcription activation by the adenovirus ElA protein. Nature 338: 39-44.

Lillie, J.W., P.M. Lowenstein, M.R. Green, and M. Green. 1987. Functional domains of adenovirus type 5 ElA proteins. Cell 50: $1091-1100$

Lin, Y.-S. and M.R. Green. 1991. Mechanism of action of an acidic activation domain in vitro. Cell 64: 971-986.

Liu, F. and M.R. Green. 1990. A specific member of the ATF transcription factor family can mediate transcription activation by the adenovirus E1A protein. Cell 64: 971-978.

Martin, K.J., J.W. Lillie, and M.R. Green. 1990. Evidence for an interaction of different eukaryotic transcriptional activators with distinct cellular targets. Nature 346: 147-152.

Moran, E. and M.B. Mathews. 1987. Multiple functional domains in the adenovirus E1A gene. Cell 48: 177-178.

Moran, E., B. Zerler, T.M. Harrison, and M.B. Mathews. 1986. Identification of separate domains in the adenovirus ElA gene for immortalization activity and the activation of virus early genes. Mol. Cell. Biol. 6: 3470-3480.

Nevins, J.R. 1992. E2F: A link between the Rb tumor suppressor and viral oncoproteins. Science 258: 424-429.

Nikolov, D.B., S.-H. Hu, J. Lin, A. Gasch, A. Hoffman, M. Horikoshi, N.-H. Chua, R.G. Roeder, and S.K. Burley. 1992. Crystal structure of TFIID TATA-box binding protein. Nature 360: 40-46.

Ptashne, M. 1988. How eukaryotic transcriptional activators work. Nature 335: 683-689.

Pugh, B.J. and R. Tjian. 1992. Diverse transcriptional functions of the multisubunit eukaryotic TFIID complex. I. Biol Chem. 267: 679-682.

Rigby, P.W.J. 1993. Three in one and one in three: It all depends on TBP. Cell 72: 7-10. 
Ruppert, S., E. Wang, and R. Tjian. 1993. Cloning and expression of human $\mathrm{TAF}_{\mathrm{II}}$ 250: A TBP-associated factor implicated in cell-cycle regulation. Nature 362: 175-179.

Sadowski, I., J. Ma, S. Triezenberg, and M. Ptashne. 1988. GAL4VP16 is an unusually potent transcriptional activator. $\mathrm{Na}$ ture 335: 563-564.

Schmidt, M.C., Q. Zhou, and A.J. Berk. 1989. Spl activates transcription without affecting the DNA binding activity of the TATA box factor. Mol. Cell. Biol. 9: 3299-3307.

Simon, M.C., T.M. Fisch, B.J. Benecke, J.R. Nevins, and N. Heintz. 1988. Definition of multiple, functionally distinct TATA elements, one of which is a target in the hsp70 promoter for E1A regulation. Cell 52: 723-729.

Spector, D.J., C.L. Parks, and R.A. Knittle. 1993. A multicomponent cis-activator of transcription of the E1B gene of adenovirus type 5. Virology 194: 128-136.

Stringer, K.F., C.J. Ingles, and J. Greenblatt. 1990. Direct and selective binding of an acidic activation domain to the TATA-box factor TFIID. Nature 345: 783-786.

Takada, R., Y. Nakatani, A. Hoffmann, T. Kokubo, S. Hasegawa, R.G. Roeder, and M. Horikoshi. 1992. Identification of human TFIID components and direct interaction between a $250-\mathrm{kDa}$ polypeptide and the TATA box-binding protein (TFIID). Proc. Natl. Acad. Sci. 89: 11809-11813.

Tanese, N., B.F. Pugh, and R. Tjian. 1991. Coactivators for a proline activator purified from the multisubunit human TFIID complex. Genes \& Dev. 5: 2212-2224.

Triezenberg, S.J., R.C. Kingsbury, and S.L. McKnight. 1988. Functional dissection of VP16, the trans-activator of herpes simplex virus immediate early gene expression. Genes \& Dev. 2: 718-729.

Webster, L.C. and R.P. Ricciardi. 1991. Trans-dominant mutants of E1A provide genetic evidence that the zinc finger of the trans-activating domain binds a transcription factor. Mol. Cell. Biol. 11: 4287-4296.

Wu, L., D.S.E. Rosser, M.C. Schmidt, and A.J. Berk. 1987. A TATA box implicated in E1A transcriptional activation of a simple adenovirus 2 promoter. Nature 326: 512-515.

Zawal, L. and D. Reinberg. 1992. Advances in RNA polymerase II transcription. Curr. Opin. Cell Biol. 4: 488-495.

Zhou, Q., P.M. Lieberman, T.G. Boyer, and A.J. Berk. 1992. Holo-TFIID supports transcriptional stimulation by diverse activators and from a TATA-less promoter. Genes \& Dev. 6: 1964-1974

Zhou, Q., T.G. Boyer, and A.J. Berk. 1993. Factors (TAFs) required for activated transcription interact with the TATA box-binding protein conserved core domain. Genes \& Dev. 7: 180-187. 


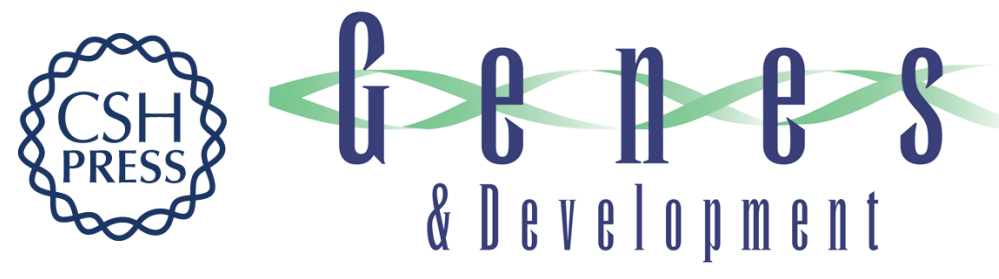

\section{Functional interaction of adenovirus E1A with holo-TFIID.}

T G Boyer and A J Berk

Genes Dev. 1993, 7:

Access the most recent version at doi:10.1101/gad.7.9.1810 $\begin{array}{ll}\text { References } & \begin{array}{l}\text { This article cites } 46 \text { articles, } 19 \text { of which can be accessed free at: } \\ \text { http://genesdev.cshlp.org/content/7/9/1810.full.html\#ref-list-1 }\end{array}\end{array}$

License

Email Alerting

Receive free email alerts when new articles cite this article - sign up in the box at the top Service right corner of the article or click here.

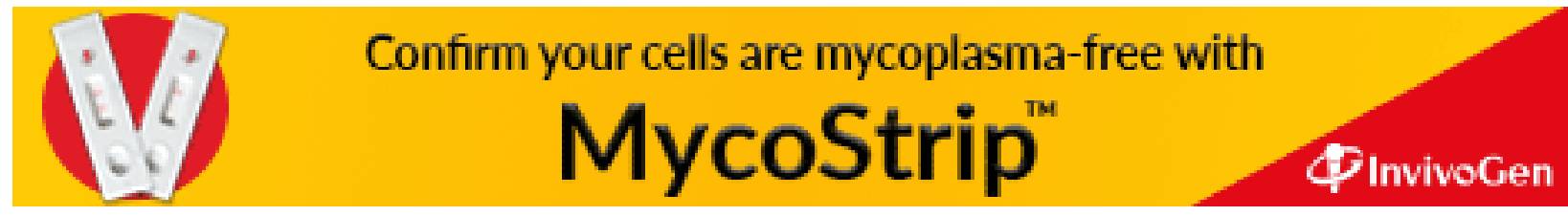

